Cadernos de História da Educação, v.20, p.1-5, e037, 2021

ISSN: 1982-7806 (on-line)

https://doi.org/10.14393/che-v20-2021-37

RESENHAS

\title{
Huellas y producciones de los estudiantes de Historia de España
}

Marcas e produções de estudantes de História da Espanha

Traces and productions of students of History of Spain

Cayetano Espejo Marín

Universidad de Murcia (España)

https://orcid.org/0000-0001-6614-1365

cespejo@um.es

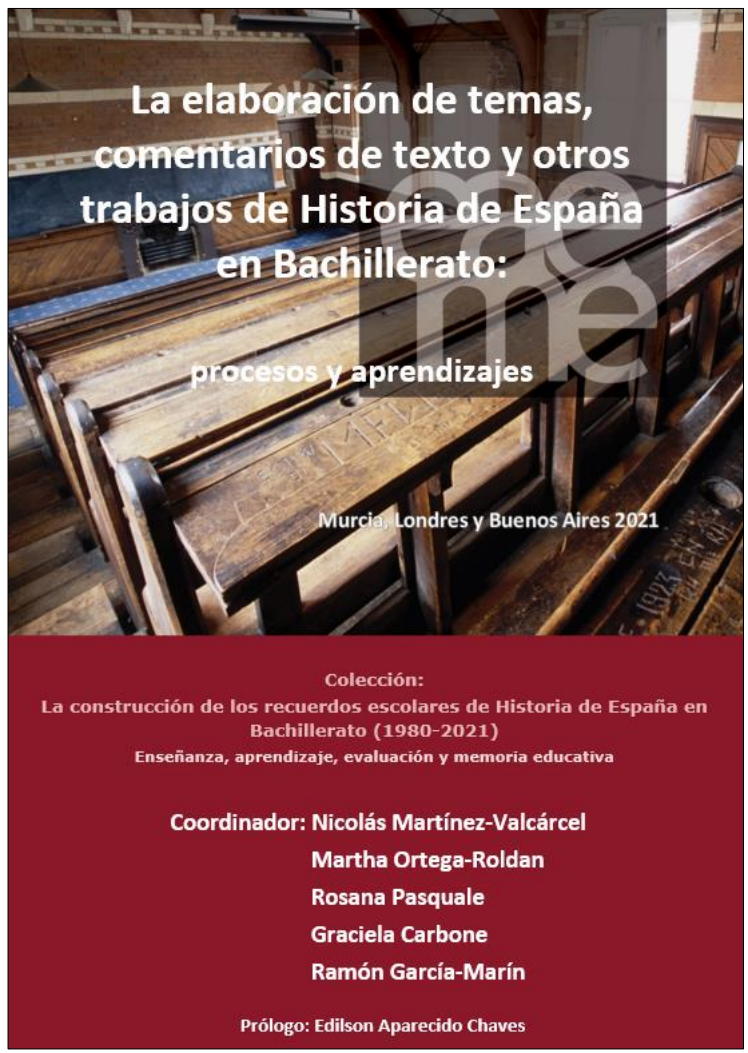

Martínez-Valcárcel, N. (Coord.), Ortega-Roldán, Pasquale, R., Carbone, G. y García-Marín, R. (2021). La elaboración de temas, comentarios de texto y otros trabajos de Historia de España en Bachillerato: procesos y aprendizajes. Murcia: Lencina-Quílez. Disponible en https://digitum.um.es/digitum/handle/10201/100404 
Como señala el título del libro, el trabajo se centra en los procesos y aprendizajes que alcanzan los alumnos mediante los temas que elaboran, los comentarios de texto que realizan y trabajos que llevan a cabo como confeccionar una charla o expresar las emociones que sienten al terminar sus estudios. Asumen los autores que esos resultados hay que entenderlos dentro del marco en el que suceden: el centro, el aula, las relaciones entre compañeros, el currículo que tienen que desarrollar, los procesos de enseñanza y las interacciones que se generan dentro y fuera del aula, las ayudas que el profesor proporciona a los alumnos, los recursos que manejan (fundamentalmente el manual y los apuntes del profesor) los trabajos que los alumnos llevan a cabo, bien en el ámbito formal (temas y comentarios de texto), como en el informal: preparar una charla sobre un tema y describir las emociones sociales que han podido generarse en el estudio de esta asignatura. Es igualmente destacable que, a cada uno de esos ámbitos -seis en total- le dedican unas conclusiones sobre los aspectos más importantes analizados y las proyecciones de futuro que tienen.

Así pues, este libro puede ser comentado a partir de diversas perspectivas, provenientes del enfoque y del ámbito disciplinar de quien lo lee, de los planteamientos que se identifican a lo largo de su lectura, o de los intereses que encaminan a su estudio, etc. Uno de los recorridos posibles puede darse a partir de lo que algunos investigadores consideran los interrogantes más significativos de la tradición del estudio de los libros de texto en el campo de las Ciencias Sociales. Formularemos dos preguntas que consideramos centrales en referencia a este campo. Una de ellas tiene que ver con el objeto denominado libro de texto y otra con la relación entre dicho libro de texto y sus interlocutores, principalmente estudiantes y enseñantes.

Respecto del primer grupo de preguntas, son numerosos los estudios que sitúan el origen de la investigación sobre los libros de texto en los interrogantes acerca de lo que lo que enseñan, de lo que no enseñan y, en particular, de lo que autorizan o buscan que sea leído "entre líneas". Numerosos estudios reconocen el origen de estos interrogantes en la obra fundadora de George Eckert, en la etapa inaugural de la Segunda Postguerra Mundial que se concretó con los años en el Instituto que lleva su nombre, comprometido con los "valores de la paz" y el reconocimiento del "otro distinto". Otras instituciones, a lo largo de la segunda mitad del siglo XX, abrieron sus espacios a estos interrogantes cuyas respuestas y nuevas indagaciones nutrieron una corriente aún joven pero caudalosa, como es la tradición ideológica. A lo largo de esas décadas, expandiéndose en el mundo, estas preguntas se entrelazaron con otras que averiguan las concepciones curriculares, psicopedagógicas, del discurso y otras, explícitas e implícitas, que inspiran las obras o de las que son portadoras.

La indagación de aquello que está oculto a las miradas no prevenidas ha venido a crear ciertos consensos, con el tiempo, acerca del escaso tratamiento que la investigación de los libros de texto presenta en la formación de los educadores.

Esta conciencia, progresivamente expandida, nos conecta con el segundo de los grandes interrogantes que pueden ser identificados en el libro que comentamos. Se trata de las aproximaciones a la investigación de la enseñanza, en aquel sector delimitado de su vasto campo que conecta a los estudiantes y a los docentes (lectores, usuarios, 
productores, ideales o empíricos) con los libros de texto y otros materiales. La postergación de las preguntas puede haber estado sostenida, a lo largo del tiempo, en una convicción tácita acerca de la autonomía profesional de los docentes. Sin embargo, el desarrollo de la investigación de las prácticas de la enseñanza, en particular, a partir de los enfoques críticos, ha generado interrogantes cada vez más significativos y consistentes. ¿Qué sucede en la realidad de los escenarios de las aulas y en los que los preceden y los suceden, tales como la casa, las bibliotecas y otros espacios en los que los estudiantes y o los docentes interactúan con los textos? Nos encontramos con otra dimensión importante que también es reconocida como escasamente investigada, cuyo núcleo de convergencia es el aquí y ahora de las prácticas del enseñar y el aprender.

En este caso, el creciente colectivo de investigadores comprometidos en el estudio de las prácticas encuentra un primer contraste entre las notas distintivas de los actores y sus escenarios y el mediador del saber representado por el libro de texto. En el primer caso, las características de singularidad, construcción inacabada, instancia de prueba de las teorías pedagógicas que conlleva el examen de su credibilidad y desafío ante la emergencia. En relación a los portadores, es decir, las propuestas editoriales, cabe destacar: la homogeneidad, el monopolio de voces y el conocimiento acabado y estable. Notas distintivas que motivaron la organización de colectivos renovadores de las prácticas y de los materiales curriculares. Rupturas valoradas por su sensibilidad a los valores de la profesión y a las realidades cambiantes de las escuelas, pero insuficientes a la hora de concretar una enseñanza renovada.

Ese movimiento renovador, al concretarse en proyectos para la investigación de las prácticas en el estudio de campo o en las escuelas encuentra otras dificultades. Las más conocidas son las condiciones burocráticas para hacer efectivo el trabajo de la investigación de campo. Otro, menos notado pero constatado, es la resistencia de los enseñantes a la apertura de las aulas (sus territorios) a las miradas externas. Sin pretender ser exhaustivos en la detección de las dificultades, otro problema no menos grave, es el de la escasez a perennidad que la investigación de campo puede lograr en referencia a la cantidad y variedad de los espacios educativos que existen. Nuevamente, una tensión: ¿pretensión de representatividad en un ámbito que es reconocido teóricamente como singular, cambiante, sembrado de incertidumbres?

De todas maneras, en los tópicos que nos ocupan las preguntas continúan vigentes: ¿Qué es lo aprendido cuando se emplean los libros de texto y otros materiales curriculares? ¿Qué es lo valorado, lo querido y lo rechazado? ¿Qué papel juegan esos recursos en el imaginario docente, en sus tareas de enseñanza y en las que las preceden y suceden? Los avances de la investigación son incipientes, pero los consensos crecientes, lo que trae consigo la sensibilización a las realidades escolares y cierto avance en el conocimiento.

De acuerdo con lo anteriormente expuesto nos preguntamos ¿Qué ofrece la obra que comentamos, en referencia a los interrogantes formulados? Volviendo al primer interrogante (acerca de los libros de texto y otros materiales, lo que enseñan, lo que ocultan, lo que jerarquizan o desplazan) los autores nos aproximan una potente introducción al estado de la cuestión en la que están presentes los fundadores del campo 
y los investigadores que, a través del tiempo, nos aproximan a las preguntas más vigentes. Ese primer acercamiento se vuelve más complejo a través de otras perspectivas que son presentadas con autonomía por parte de los autores, pero también integrándolos para iluminar el objeto de estudio: las aportaciones de las psicologías cognitivas que hacen foco en la enseñanza y el aprendizajes de las Ciencias Sociales, los enfoques políticos, de la Didáctica y de la Lingüística que contribuyen a formularse preguntas acerca de los escenarios poblados de las aulas, de los estudios solicitados, de las interacciones grupales, de las producciones que el alumnado lleva a cabo y también de cómo va construyéndolas personalmente y con la ayuda del profesor.

¿Cómo nos acerca la obra a ese estudio? Diríamos, ateniéndonos al diseño de investigación y a sus concreciones, que se trata de realidades construidas en el tiempo, a posteriori de los hechos, que han sido recobradas por los interrogantes de la investigación.

En primer lugar, las "huellas". Se trata de indicios del quehacer de los actores, en las aulas, en el manejo de los materiales, que son marcas que poco dicen a las miradas desprevenidas, pero que a partir de las observaciones pacientes, sostenidas y sustentadas en la reflexión informada, construyen datos para edificar, desde distintos enfoques, un saber sobre la enseñanza y los aprendizajes. Así pues, subrayados, tachaduras, notas al margen, apuntes anexos, cobran vida a la luz de otras lecturas para las que no fueron realizados, recordemos que eran para comprender y superar esta asignatura. Estructurar esos indicios, analizar las producciones en los apuntes de los profesores, en las pruebas de los estudiantes, en las intervenciones de los docentes y en las revisiones de los alumnos, es un trabajo que produce nuevos saberes: perfiles de la enseñanza, sujeciones de los educadores a las regulaciones curriculares, resistencias, presencia de la cultura de la evaluación, rescate de las subjetividades de los actores protagonistas de la enseñanza.

La obra que analizamos aporta construcciones de esa realidad a lo largo del tiempo, a partir de una variedad de textos y soportes cuya organicidad es producto de trabajos de observación, registro y sistematización a lo largo de cuatro décadas de investigación y que contribuyen a historiar las prácticas de la enseñanza y de las concepciones explícitas o tácitas que las plasmaron en lo documentado.

Esta construcción se ha generado en el tiempo, por el cruce de labore s provenientes de las disciplinas en juego, que acordaron hacer foco en la materialidad de los portadores del saber curricular y en los actores, docentes y discentes, que dejaron testimonio de sus labores en las lecturas, en las escrituras y en las evocaciones suscitadas por los investigadores. Otro rasgo que identifica la obra es el cierre de cada apartado, con aperturas a nuevos interrogantes en los que el lector es invitado a participar, a sugerir nuevas ideas o revisar las explicadas...

En una etapa histórica en que la investigación evaluativa gana espacios y presiona a la construcción de criterios y parámetros de evaluación homogeneizadores, un trabajo paciente de indagación en la singularidad de los centros educativos y en la construcción de regularidades no arbitrarias ofrece un contraste sugerente que, probablemente, invite a replicar estos esfuerzos en otros ámbitos. Invitamos a la lectura del libro o de los artículos de síntesis que han elaborado los autores en español, portugués, francés e inglés. 


\section{Referencias}

Os materiais, o trabalho dos alunos e as marcas no ensino da História da Espanha: estudo de caso. Disponible en: https://www.researchgate.net/publication/350193575

Les matériels, les travaux des étudiants et les traces dans l'enseignement de l'Histoire d'Espagne: une étude de cas. Disponible en: https://www.researchgate.net/publication/349809323

Los materiales, los trabajos del alumnado y las huellas en la enseñanza de la Historia de España: Estudio de caso. Disponible en: https://digitum.um.es/digitum/handle/10201/104401

Martínez-Valcárcel, N., Ortega-Roldán, M., García-Marín, R., Pasquale, R., Carbone, G., \& Chaves, E. A. (2021). Materials, student's work and her traces in teaching History of Spain: a case study. International Journal of Humanities and Social Science, 11(2), 27-43. http://dx.doi.org/10.30845/ijhss.v11n2p4

Martínez-Valcárcel, N. (Coord.); Ortega-Roldán, M; Carbone, G., Pasquale, R.; García Marín, R. y Chaves, E.A. (2021b). Participante 3007. Documentación utilizada. Colección: La construcción de los recuerdos escolares de Historia de España en Bachillerato (1980-2021). Murcia: Lencina-Quílez. Disponible en: https://www.researchgate.net/publication/351484177_PARTICIPANTE_3007_DOCUMENT ACION_UTILIZADA\#fullTextFileContent 